\title{
Discussion on Integrated Specialty Reform of Communication
}

\section{Engineering}

\author{
Jun Zhu, Xiao-Hui Li, Yu-Fa Sun \\ Key Laboratory of Intelligent Computing \& Singnal Processing, Ministry of Education, School of \\ Electronic Information Engineering, Anhui University Hefei, P.R. China \\ junzhu@ahu.edu.cn,xhli@ahu.edu.cn,yfsun@ahu.edu.cn
}

Keywords: communication engineering specialty, talents training mode, integrated specialty reform, practice teaching link.

\begin{abstract}
Communication engineering specialty is an engineering practical and very strong applied specialty. Practice teaching plays an important role of cultivating students' scientific thinking methods, scientific research ability and innovation ability. Through integrated specialty reform, we improve the practice teaching conditions further, optimize the practice teaching content, innovate the teaching mode, strengthen the teaching team and promote the combination of the cultivation of talents, production-practice and social practice, thus improving students' innovation consciousness and practice ability.
\end{abstract}

\section{Introduction}

The communication engineering specialty of Anhui University was set up in 1994. More than one thousand students graduated from the specialty. The professional knowledge structure of teachers from the specialty is reasonable and most teachers have doctorates. We do not have rich experience in engineering, but teachers participated in electronic design and innovation competition organized by national, provincial or Anhui University, and achieved remarkable results. We have experience in guiding students in social activities. According to the educational philosophy " Out-standing Engineers Training Plan", "Facing the industry, facing the future, facing the world" put forward by the Ministry of Education, we combine with the development of the professional status and trends, keep up with the latest theoretical research at home and abroad, and practice development and application results. Therefore, it is quite meaningful for integrated specialty reform of communication engineering.

\section{Present Situation of Communication Engineering Education Practice}

For a long time, the communication engineering specialty has seized opportunity to provide students with internship conditions. They arrange students to take part in the electronic engineering comprehensive experiment, comprehensive experiment, and a series of metalworking practice, professional practice and internship. In September of each year, students major in this department will accept the radio frequency training for two weeks in innovation laboratory in our university (Project supported by the Ministry of Finance). Time is not sufficient, but it can effectively improve students in product and engineering project design and management experience, and cultivate the students' professional ethics and sense of responsibility, engineering quality and innovation ability, so comprehensive effect is obvious. In addition, Anhui radio and television launch pad of Dashushan, Anhui Sun-Create Electronics Co,Ltd, Hefei BoLun microwave devices co,LTD and other units are all our department agreement practice base. Each fall semester, communication engineering department will look for opportunities to organize students to participate in the production line. Combined with on-site teaching and through face-to-face interaction with engineering and technical personnel, students can experience the enterprise operation and management mode profoundly, and the ability to adapt to society is also enhanced obviously. 
Although the internship of this specialized students has obtained certain results, the existing practice mode is still difficult to meet the social demand and far away from the enterprise expectations of talents. The employers complain that the students' practical working experience is too little, and the practice ability is much poor generally. Especially, communication network is developed rapidly and network design technology is applied widely. Therefore, it is necessary to seize the rare opportunity of building characteristic discipline of "communication engineering" and integrating resources of university and enterprise to complete reform of communication engineering specialty.

\section{Construction of Patterns of Nurturing Innovation Talents for Communication Engineering}

To construct patterns of nurturing innovation talents for communication engineering, the kernel should be enhancing the capability of practice, design and innovation of communication engineering. And the curriculum and teaching content should be reformed and reconstructed. On the basis of the position of the very subject, its objective of personnel training and its specialties and advantages, the major fields and personnel training levels of the plan of cultivating innovative talents should be settled, and in line with the general and professional standards, the standard of training system of communication engineering should be set up which consists of establishment of training standard of communication engineering talent-nurturing planning, refining professional standards of communication engineering into knowledge and ability outline, the reform of curriculum and teaching content, and the completion of culturing standard matrix.

With the implement of this project, students will participate in kinds of engineering practice activities to strengthen their practice capability and increase their skills in engineering. Platforms shall be offered for fine training, skill support and professional experiment, scientific research training and field work in one hand. In the other hand, students should be actively organized to declare all kinds of college students' innovative experimental programs. Meanwhile, they are actively organized and selected to participate in the Electronic Design Contest, "Challenge Cup" Scientific and Technological Works Competition, Aerospace Models Championship, Radio Direction Championship, Embedded Processor Design Application Contest, Innovation and Entrepreneurship Competition and other college students' scientific and cultural competitions, so as to train a number of the talents of excellent communication engineering.

Centering on the core-courses, two or three teachers will be trained to be academic pilots or great teachers with international vision. Under whose guidance, the teaching team personnel training project will be carried out and scientific researches will be conducted. We strive for a communication engineering teaching team with internally fist-class teaching and scientific research and with certain international influence and fame.

Two professionals will be selected and designated annually to China Unicom and Institute of Communication Planning and Designing for learning and exchange. It will improve the current teachers' engineering background. In the meantime, one or two technocrats, senior administrators and skilled engineers in communication field will be invited and employed as adjunct professors to give lessons and lectures.

Two to four professional teachers will be supported to attend teaching and scientific research meetings home and abroad. Inter-university cooperative relationship will be established widely to learn the latest reform and trend in domestic and international education. By talent introduction and self-cultivation, we strive to obtain the goal that for teachers under the age of $45,100 \%$ of them shall have master degree and at least $50 \%$ should have $\mathrm{PhD}$.

\section{Construction of Curriculum and Teaching Resources}

In accordance with the guiding ideology and training objective of the discipline development, the curriculum and teaching contents will be further optimized, students' innovative awareness will be heightened and their practice ability will be developed. We have more clear knowledge about the 
curriculum and teaching's role and function and requirement in the personnel training project to strengthen the foundation and highlight the core courses.

The course construction includes core-courses construction, teaching material construction, and teaching resources construction and so on. This project will focus on the frontier of electronic information technology and will make overall plans and take great care to build 12 special course groups. The first group is that of circuit, which is made up of Basic Circuit Analysis, Communication Electrical Circuit, and Digital Circuit and Logic Design. The second one is a series of computer courses which includes C Language Programming, and Principles and Application of Personal Computer. The third one is about signal and information processing courses which includes Signals and Linear System, and Digital Signal Processing. The fourth one is about communication technology which composes of Communication Principle, and Mobile Communication. The fifth is abutting circuit and system design which includes Electronic Circuit Course Design, and Digital Information Processing Course Design. The course groups will integrate the core-courses and avoid the overlap between relative courses, and at the same time it will benefit the teachers to carry out education and teaching research activities and to explore ways to reform the teaching methods, and students will gain benefits to have a quick grasp of the knowledge and foster a systematic learning, increase their innovation awareness and their ability of engineering practice.

A team of members with considerable teaching experience and enormous capability in scientific research will be organized to compile academic works up to high standard and teaching materials for core-courses like Digital Circuit and Logic Design, Principles and Application of Personal Computer, and Modern Communication System and Communication Network. The current hot communication technology and the latest research achievements will be absorbed in teaching materials. Our objective is that three to five textbooks will be published, and five to seven courses will

\section{Reform of Theory Teaching Method and Practice Teaching Link}

Project-driving and open teaching methods are adopted. For the project-driving teaching method, the project design is the main thread, teachers are the leaders and students are the main body. During the course of implementing the project-driving teaching method, the theme of project design will be selected to encourage students to innovate in light of the course characteristics and students' knowledge structure. The analysis and debugging in the course of project designing will help students have more profound understanding of professional knowledge, and foster their innovation ability and practice capability and their team mentality. The open teaching method will heighten students' innovation awareness and increase their capability in scientific research through lectures, research and hobby group and scientific research training. With the permeation of corecourses in kinds of scientific and technologic and cultural competitions, these competitions will advance teaching and strengthen practice skills. The visual demonstration or combination of theories with experiments will reinforce their perceptual knowledge and inspire their interests and confidence in practice. With the reform in evaluation, various evaluation systems will be adapted. For courses that need much practice and experiment, we will adapt the evaluation method of paper report plus material object, which will have an overall assessment of the students' capability for practice, innovation and teamwork, linguistic competence, and the ability to obtain information and application.

Combining with the characteristics of communication engineering and the talents training requirements, we increased the proportion of practice teaching and make professional practice teaching above 48 credits, which occupies over $30 \%$ of the total credit. We should perfect the professional communication laboratory and also increase a batch of comprehensive and designing experiments which reflect the new technology and the new development of communication. Then 
we can give students more opportunities to explore research and do applied experiments, improving students' professional skills.

2-3 new off-campus practice bases are constructed. Students have more opportunities to join the production line for field work. They will understand the actual production process and strengthen their practice ability. At the same time, we invite the enterprise engineering and technical workers to open the teaching lecture and guide the students to innovate and make the graduation design. We improve the existing innovation laboratory and carry out comprehensive, multi-level, technical and innovative activities, enhancing the participation and influence of the science and culture competition. We make use of the professional teachers' academic atmosphere and the scientific research achievements to inspire students' interest in learning and scientific research. More and more students enter the research lab and accept scientific training, laying a good scientific foundation for future work.

\section{Acknowledgment}

The work is supported by the quality engineering project of " 211 project” of Anhui University.

\section{References}

[1] Peng Liangfu, Zhang Chuanwu. Taking employment as the orientation to construct the applied communication engineering specialty $[\mathrm{J}]$. Teaching and teaching research, Vol.23, No.12 (2009), p. 58-59

[2] Jun Zhu,Yanjun Hu. Application of project teaching method in digital signal processing[C], International Conference on Computer Science and Education,ICCSE (2012),p. 1789-1791

[3] Zhujun ,Sun Yufa, Xu Xianfan. Discussion on Navigation Course of Electricity and Communication Engineering Specialty [J]. Forum of Education Teaching, Vol.11, No.39 (2012), p. 146-148

[4] Zhang Anfu, Liu Xingfeng.Reflection on the Implementation of “A Plan for Educating and Training Out-standing Engineers”[J].Research on Senior Engineering Education, No.4 (2010), p. 56-59

[5] Chen Xinyan, Zhang Anfu. Training Mode of Germany Engineers and Reference Value [J].Global Vision Theory Monthly , No.10,(2008) ,p. 166 -168 